\title{
Ink-Jet Printing of Wax-Based Alumina Suspensions
}

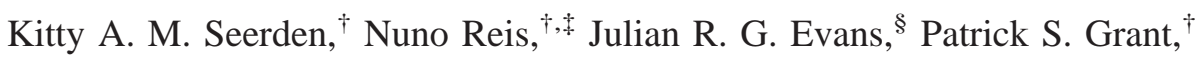 \\ John W. Halloran, ${ }^{*, I I}$ and Brian Derby ${ }^{*, *}$ \\ Department of Materials, University of Oxford, Oxford OX1 3PH, United Kingdom; Manchester Materials Science Centre, \\ UMIST, Manchester M1 7HS, United Kingdom; Department of Materials, Queen Mary and Westfield College, \\ University of London, London E1 4NS, United Kingdom; and Department of Materials Science and Engineering, \\ University of Michigan, Ann Arbor, Michigan 48109-2136
}

\begin{abstract}
Suspensions of fine alumina powder in a paraffin wax have been successfully formulated with viscosity values sufficiently low to allow ink-jet printing using a commercial printer. A commercial-grade paraffin wax, with stearylamine and a polyester, were used as the dispersant system. Suspensions with powder loadings up to 40 vol\% were passed through the ink-jet printer head. Unfired ceramic bodies with a feature size of $<100 \mu \mathrm{m}$ have been successfully fabricated with waxes that had a powder loading of $30 \mathrm{vol} \%$. The influence of suspension fluid properties on the ink-jet printing process has been studied, and the importance of the acoustic resonance within the ink-jet printing apparatus has been demonstrated.
\end{abstract}

\section{Introduction}

NK-JET printing is a mature technology with many applications. Originally developed as a contactless printing method, it is now routinely used for personal printing, commercial printing, product marking, microdosing, rapid prototyping, and rapid manufacturing. It has been explored for several years as a tool for ceramic fabrication via the deposition of a binder onto a powder bed. ${ }^{1,2}$ Direct ink-jet printing of ceramic slurries is potentially a very versatile method for the manufacture of ceramic parts. Using multiple printing jets, components with a composite architecture or graded composition can be fabricated. Substantial work has been performed on the ink-jet deposition of ceramic powders in aqueous or alcohol suspensions, chiefly on the deposition of $\mathrm{ZrO}_{2}$ suspensions, by Evans and co-workers. ${ }^{3-6}$ One of the current authors has successfully printed lead zirconate titanate (PZT) suspensions. ${ }^{7}$ In all these cases, the printer used was a commercial printer that was developed for printing on paper. These printers currently have lateral resolutions up to $\sim 1200 \mathrm{dpi}(\sim 20 \mu \mathrm{m})$. Ink-jet printing of ceramics using these printers requires the development of a ceramic "ink" with similar fluid properties to the dye- or pigmentbased inks used for reprographic applications. These inks dry via absorption and evaporation and typically contain $\sim 5-10$ vol\% solids.

Hot-melt or phase-change printing represents a second ink-jet printing technology that also has been originally developed for reprographic applications. This process uses a dye or pigmented suspension that solidifies on impact cooling. This technology was

L. Bergstrom-contributing editor

Manuscript No. 188045. Received January 2, 2001; approved July 5, 2001.

The authors would like to acknowledge the support of the EPSRC, through Grant No. GR/L42537, awarded by the Materials Programme. Author JWH was supported through the EPSRC Visiting Fellowship programme (No. GR/L42551).

${ }^{*}$ Member, American Ceramic Society.

†Dept. of Materials, University of Oxford.

*Manchester Materials Science Centre, UMIST

${ }^{\S}$ Dept. of Materials, Queen Mary and Westfield College, University of London.

IIDept. of Materials Science and Engineering, University of Michigan. developed to eliminate the drying cycle, because of the risk of smudging during printing. The ink-jet deposit forms a splat of greater height than that of conventional fluid inks; thus, overprinting can be used to build up a significant deposit thickness. Hot-melt printers can be purchased for pattern making and object visualization. These commercial machines are ideally suited for droplet-based rapid manufacturing, because they are capable of building solid objects from many standard-format computer-aided design (CAD) files.

Ink-jet printers generate and position droplets using one of two different mechanisms: continuous ink-jet printing or drop-ondemand printing. In continuous ink-jet printing, a stream of fluid is passed through a small orifice. The stream disperses into small droplets by Rayleigh instability; this activity is normally controlled by a small, superimposed mechanical oscillation. If an electric charge is imparted to the drops, these drops can subsequently be steered by applying an electrostatic field. Drops not required for printing are captured and recirculated. In drop-on-demand ink-jet printing, the drops are only formed when required and position control is achieved by mechanically positioning the printer head above the desired location before drop ejection. Both methods of ink-jet printing have been used successfully to build ceramic objects. $^{4,5}$ Continuous ink-jet printing operates at much-faster droplet-generation rates than drop-on-demand printers; however, the need to use an electrically conducting fluid and the possibility of contamination during the recirculation process limit the ceramic applications. Hence, for this study, we have confined our attention to drop-on-demand printing. In earlier work, ${ }^{8,9}$ we demonstrated the feasibility of passing ceramic slurries with solids loadings up to $\sim 20$ vol\% through a commercial drop-on-demand hot-melt ink-jet printer (Modelmaker MM6 Pro, Solidscape, Inc., Merrimack, NH).

The fluid dynamics of drop-on-demand ink-jet printing have been studied for some time. Drop formation is initiated by applying a pressure pulse to a fluid-filled chamber with a small opening. This action leads to ejection of a column of liquid and a droplet forms, which is projected away from the opening. Fromm ${ }^{10}$ obtained an approximate solution to the Navier-Stokes equations for the case of droplet ejection. In his analysis, he used a characteristic dimensionless grouping of physical constants - the ratio $\mathrm{Re} / \mathrm{We}$ (where Re the Reynolds number and We is the Weber number) - that is representative of the influence of the viscous, inertial, and surface-tension forces on fluid flow:

$$
\frac{\mathrm{Re}}{\mathrm{We}}=\frac{(\gamma \rho a)^{1 / 2}}{\eta}
$$

where $a$ is a characteristic length; $\rho, \gamma$, and $\eta$ represent the density, surface tension, and viscosity of the fluid, respectively. $\mathrm{Re}=$ $v a \rho / \eta$ and $\mathrm{We}=v(a \rho / \gamma)^{1 / 2}$. This ratio (Re/We) is the inverse of the Ohnesorge number, $\mathrm{Z}=\eta(\rho \gamma a)^{-1 / 2}$ and is independent of fluid velocity. In most commercial drop-on-demand printing platforms, this dimensionless grouping has a value of $1-10$. The influence of this ratio on ink-jet behavior can be explored through fluid-dynamics simulation. ${ }^{11}$ If this ratio is too small, the viscous 
term is dominant and a large pressure pulse is required to eject a droplet. A high value of the ratio leads to very large liquid-column extensions before droplet formation. Such long columns can also lead to satellite drop formation behind the main drop. Small Re/We values lead to low droplet velocity and shorter column extensions before droplet ejection.

Another important fluid-controlled parameter in ink-jet printing is the extent of droplet spreading that occurs during impact. This parameter defines the lateral resolution of the system and the thickness of each deposited layer. Many algorithmic approximations to predict this parameter exist; all are based on an energy balance of the surface and kinetic energy of the drop in flight, versus the surface energy of a deformed drop and the viscous work done during drop deformation on impact. The present study uses the expression derived by Bhola and Chandra ${ }^{12}$ for an experimental study of the impact cooling of paraffin-wax drops. This relation defines the maximum extent of droplet spreading in the absence of solidification $(\xi)$ as

$$
\xi=\frac{r_{\max }}{r}=\left[\frac{\mathrm{We}^{2}+12}{3(1-\cos \theta)+4 \mathrm{We}^{2} / \mathrm{Re}^{1 / 2}}\right]^{1 / 2}
$$

where $r_{\max }$ and $r$ are the maximum splat radius and initial drop radius, respectively, and $\theta$ is the equilibrium contact angle that the droplet makes with the substrate.

To ensure dimensional stability - and, in the case of multiple material jetting, deposit homogeneity - the impacting droplets should not splash. The splashing of liquid drops has been studied by Mundo et al., ${ }^{13}$ as well as by Stow and Hadfield. ${ }^{14}$ They both found that splashing occurred when the parameter $K$ exceeded a critical value $K_{\mathrm{c}}$ :

$$
K=\mathrm{WeRe}^{1 / 4}
$$

For water and methanol, $K_{\mathrm{c}}=57.7 ;^{13}$ for paraffin wax, $K_{\mathrm{c}}=102$ for a cold surface $\left(23^{\circ} \mathrm{C}\right)$ and 137 for a hotter surface $\left(73^{\circ} \mathrm{C}\right) .^{12}$

Thus, ink-jet printing behavior is strongly controlled by the fluid properties of the material to be printed, as well as the velocity of the liquid drops and their size. With ceramic slurries, viscosity is expected to be the fluid property that shows the strongest dependence on the volume fraction of particles present. The surface tension of the fluid also may be influenced by the surfactant properties of additives used to stabilize the ceramic suspensions. The quality and definition of a ceramic body that has been produced by ink-jet printing should be dependent on the We and $\mathrm{Re}$ values of the printing fluid. In this study, we have used these parameters as a guide to the design of fluid properties to allow the ink-jet printing of ceramic suspensions. Thus, we have made the reasonable assumption that the fluid properties of ceramic suspensions can be treated as if they are homogenous fluids, as long as the suspended particle size is significantly smaller than the smallest linear dimension of the fluid flow.

\section{Materials Used and Experimental Conditions}

A model system that was based on alumina powder ( $\alpha$-alumina, Product RA45E, Alcan Chemicals, Burntisland, Fife, U.K.) with a mean particle size of $400 \mathrm{~nm}$ and specific surface area of $8.2 \mathrm{~m}^{2} / \mathrm{g}$ was used. This powder was dispersed in a low-melting-point commercial-grade alkane (paraffin) wax (Mobilwax 135, Mobil Special Products, Milton Keynes, U.K.) with a melting temperature of $57^{\circ} \mathrm{C}$; this wax had a viscosity of $2.8 \mathrm{mPa} \cdot \mathrm{s}$ and density of $780 \mathrm{~kg} / \mathrm{m}^{3}$ at $100^{\circ} \mathrm{C}$. This system was selected because of our previous experience in using it for ceramic processing applications. ${ }^{15}$ To produce stable suspensions of the alumina, a dispersant system was selected, using a commercial, polymeric dispersant (Hypermer FP1 or Hypermer LP1, Uniqema (formerly ICI Surfactants), Everberg, Belgium) in combination with short-chain organic compounds, stearic acid (1-octadecanoic acid, BDH Laboratory Supplies, Poole, U.K.), or stearylamine (1-octadecylamine, Lancaster Synthesis, Morecambe, U.K.). According to the manufacturers, the two grades of dispersant contain the same functional

groups and differ only in molecular weight. ${ }^{16}$ Suspensions were prepared by melting the wax and mixing the dispersants and organic additions under gentle stirring. Then, the suspended ceramic slurries were poured into high-density polyethylene bottles that contained $\mathrm{ZrO}_{2}$ milling media before the alumina powder was added. Then, this mixture was ball-milled inside an oven at a temperature of $120^{\circ} \mathrm{C}$ for $3.6 \times 10^{4} \mathrm{~s}(10 \mathrm{~h})$ to produce a stable, dispersed slurry. Then, the suspensions were filtered by passing them through a stainless-steel wire mesh $(\sim 30 \mu \mathrm{m}$ aperture $)$ before finally allowing them to solidify and cool to room temperature.

The slurries were characterized for their rheological properties using a concentric cylinder rheometer (Model RSIII, Brookfield Engineering Laboratories, Middleboro, MA). This apparatus was connected to a recirculating oil bath, to provide a stable elevatedtemperature environment. Measurements were made at shear rates of $3-300 \mathrm{~s}^{-1}$ after an equilibration period of $30 \mathrm{~s}$. The range of rates over which the measurements could be made is limited by the shear stress that is developed in the suspension. Thus, the range of accessible shear rates decreases as the suspension viscosity-and, hence, solids particle loading-increases.

The formation of liquid droplets during ink-jet deposition was characterized by monitoring a single jet using a dedicated jet test station, which consisted of a single drop-on-demand piezoelectric jet head assembled with a heating jacket (Sanders Design International, Wilton, NH). This apparatus allows control of the driving pulses, which are used to fire the ink jet (pulse amplitude, duration, and peak shape), and the fluid temperature. Drops can be imaged using a stroboscopic system synchronized with the ink-jet firing pulse. The stroboscopically backlit images were captured using a charge-coupled device (CCD) camera system. By introducing a delay between the firing pulse and the stroboscopic illumination, the motion of the drops can be tracked until they impact the target surface. An example image from the test station is given in Fig. 1. The mean droplet velocity can be determined from the spacing between the droplets and the frequency of operation. The mean droplet mass can be determined by collecting and weighing a known large population of drops after printing. Printing trials were conducted using the same type of printer as that used previously 8,9 (Modelmaker MM6 Pro).

(a)

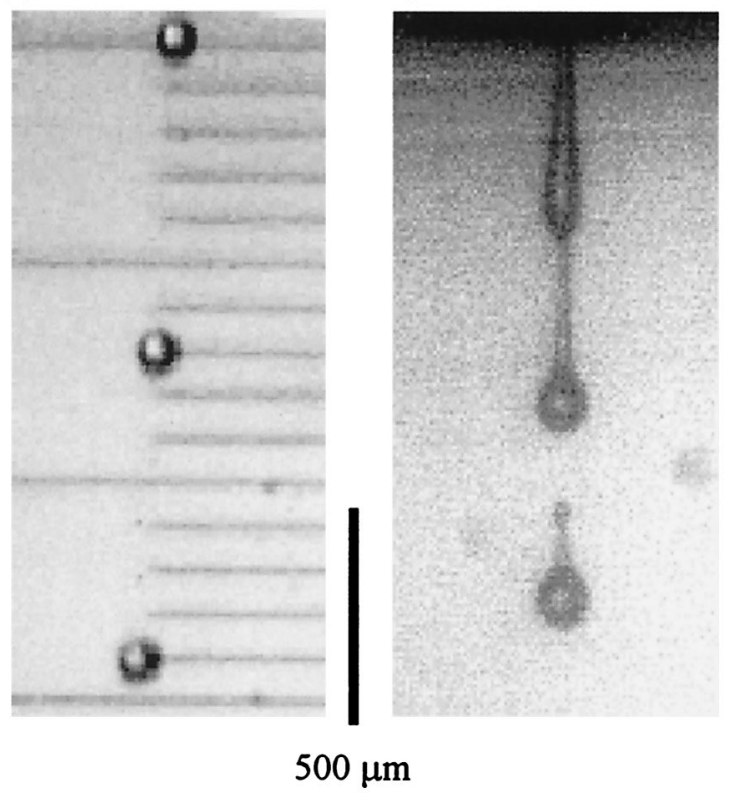

Fig. 1. In situ stroboscopic images of the droplets that form near the ink-jet printing head; fluid is "Protobuild," drop volume is $500 \mathrm{pL}$, and velocity is $7 \mathrm{~m} / \mathrm{s}$. Note the characteristic tear shape drop in Fig. 1(b) that occurs near the printing orifice. Minor scale division is $100 \mu \mathrm{m}$. 


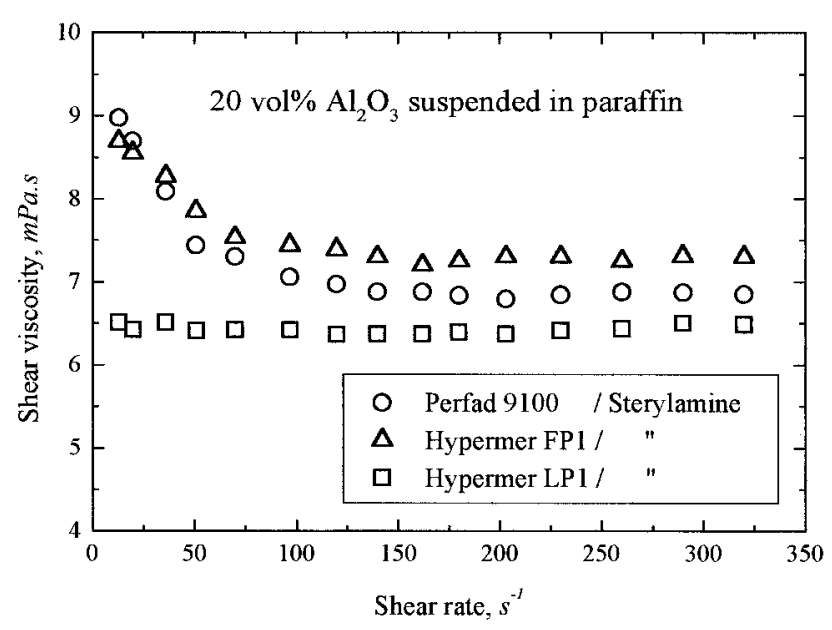

Fig. 2. Shear viscosity of a $20 \mathrm{vol} \% \mathrm{Al}_{2} \mathrm{O}_{3}$ suspension in paraffin wax, measured over a range of shear rates. Results using a range of commercial dispersants are shown.

\section{Results and Discussion}

\section{(1) Suspension Rheology}

From the range of dispersant and organic compound compositions tested, Hypermer LP1 combined with stearylamine was determined to provide the best results, in terms of suspension stability and low viscosity. Figure 2 shows the relative behavior of a $20 \mathrm{vol} \%$ suspension of $\mathrm{Al}_{2} \mathrm{O}_{3}$ in paraffin wax (compositions are indicated in Table I). The suspension using the LP1 dispersant shows lower viscosity and reduced shear thinning, when compared with the suspensions that used other dispersants, over the shear rates that have been measured.

To minimize distortion during removal of the suspending vehicle and subsequent sintering, it is necessary to produce a suspension of the ceramic with a high loading of solid particles. The viscosity is known to increase as the fraction of particles in suspension increases. Figure 3 shows the measured viscosity of the alumina suspensions, as a function of the volume fraction of ceramic particles in suspension. The solid line shows the predicted rheological behavior of such a suspension using a modified Krieger-Dougherty model:

$$
\frac{\eta}{\eta_{0}}=\left(1-\frac{\phi}{\phi_{\max }}\right)^{-n}
$$

where $\eta$ and $\eta_{0}$ are the viscosities of the suspension and the unloaded fluid, respectively; $\phi$ is the volume fraction of particles, $\phi_{\max }$ the maximum volume fraction before a rigid network forms, and $n$ a characteristic constant. The best fit to the data is found using values of $n=2$ and $\phi_{\max }=0.53$. This value for $\phi_{\max }$ is rather low and is partly due to the steric stabilizing layer increasing the effective particle radius. ${ }^{17}$

A solids volume fraction of $40 \%$ has been arbitrarily taken as representing the minimum powder fraction from which a sinterable ceramic compact can be obtained. Shrinkage on wax solidification and during wax removal can be reasonably expected to increase the packing efficiency toward $50 \%$ before sintering. To optimize the suspension to obtain the lowest possible viscosity at a $40 \mathrm{vol} \%$ solids loading, a systematic variation of the amounts of stearylamine and LP1 was used. These results are illustrated in Fig. 4 as a contour map of viscosity as a function of composition. The lowest viscosity is observed in the range of $1 \%-1.5 \%$ LP1 with a stearylamine:LP1 ratio between 1:2 and 1:3. Excess quantities of stearylamine and LP1 increase the viscosity of the suspension. In the absence of alumina, LP1 increases the viscosity of the paraffin wax. At low concentrations of LP1, this action results in an increase of $\sim 10 \%$ in viscosity per $1 \%$ of LP1 added.

Using the above-noted data to optimize the rheological properties of the ceramic suspension, a series of ceramic slurries that contained up to $40 \mathrm{vol} \%$ alumina particles was prepared. Table II compares the fluid properties of these suspensions with those of "Protobuild" and "Protosupport" (fluids used commercially with the Modelmaker MM6 Pro printer for rapid prototyping), measured at temperatures of $120^{\circ}$ and $110^{\circ} \mathrm{C}$, respectively. The unfilled wax has a much-lower viscosity than the two commercial fluids and, hence, a larger Re value. As the particle loading of the ceramic suspension is increased, the fluid density and viscosity increase, which leads to a rapidly decreasing Re value. We were not able to measure the surface tension of the filled waxes; instead, we have assumed that the value remains unchanged from that of the unfilled wax. However, because of the increase in density with an increased volume fraction of particles, the We value decreases. At a particle loading of $\sim 30 \mathrm{vol} \%$, the properties of the ceramic slurry at $100^{\circ} \mathrm{C}$ are very similar, in terms of $\operatorname{Re} / \mathrm{We}, K$, and $\xi$, to the values recorded for the Protobuild and Protosupport fluids at their normal printing temperatures.

Note that we have chosen to measure all rheological properties in a fairly narrow range of temperatures, despite the fact that the fluid viscosity decreases rapidly as the temperature increases. This concession is made because we are constrained by the range of temperatures over which the ink-jet heads can operate.

\section{(2) Fluid Jetting Behavior}

Piezoelectric drop-on-demand ink-jet printers operate by the acoustic excitation of a fluid-filled chamber. Figure 5 shows a section through a simple "squeeze-tube" printing device where the application of an electric field across the piezoelectric tube induces a change in chamber volume. In the Sanders Modelmaker MM6 Pro printer, a similar actuation configuration is used. The chamber first expands and fluid enters from the reservoir via a combination of the reduced pressure and the pressure difference associated with the meniscus at the printing nozzle and the hydrostatic head. Then, the chamber closes, which induces a compressive pressure pulse that propagates through the liquid in the chamber. The open jet acts as a valve in which capillary pressure contains the liquid unless a sufficiently large pressure pulse ejects a drop. To achieve rapid building rates, the printing head is excited at high frequency; in the case of the Modelmaker MM6 Pro printer, this frequency is $6 \mathrm{kHz}$. Thus, the important machine variables for printing using drop-ondemand ink-jet technology include the following: the voltage used to excite the piezoelectric actuator, the driving frequency (these two factors control the fluid pressure pulse), the shape of the driving pulse, the chamber static pressure, and the temperature. The jet-test station has been used to investigate the influence of

Table I. Composition of Wax-Based Suspensions Used in Preliminary Viscosity Trials and Optimized Suspensions Used for Ink-Jet Printing ${ }^{\dagger}$

\begin{tabular}{|c|c|c|c|c|}
\hline $\begin{array}{l}\text { Nominal } \mathrm{Al}_{2} \mathrm{O}_{3} \text { loading, } \\
\text { in suspension (vol\%) }\end{array}$ & Surfactant type & Alumina content (wt\%) & Surfactant content (wt $\%$ ) & Stearylamine content (wt $\%$ ) \\
\hline 20 & Perfad 9100 & 53.16 & 1.20 & 1.20 \\
\hline 20 & Hypermer FP1 & 53.16 & 1.20 & 1.20 \\
\hline 20 & Hypermer LP1 & 53.16 & 1.20 & 1.20 \\
\hline 30 & Hypermer LP1 & 65.47 & 0.65 & 0.33 \\
\hline 40 & Hypermer LP1 & 74.63 & 0.75 & 0.37 \\
\hline
\end{tabular}




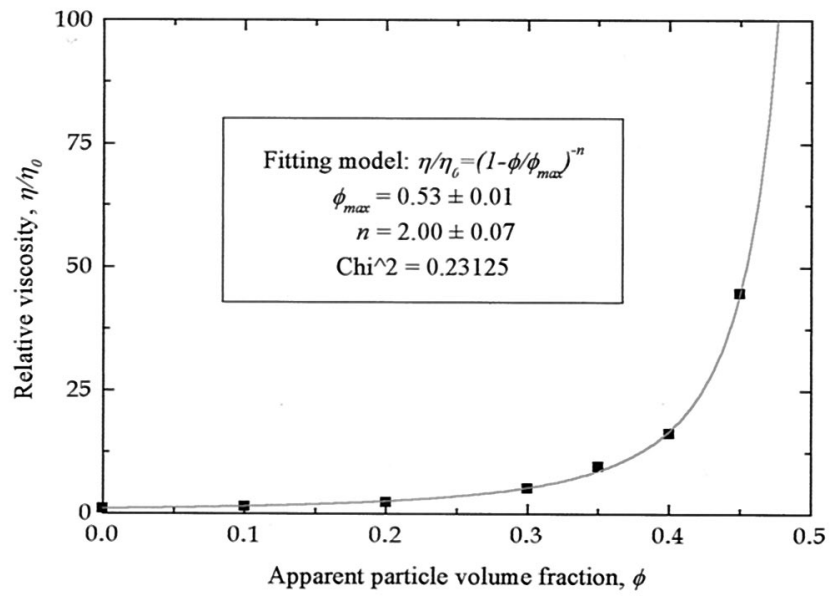

Fig. 3. Viscosity of the alumina/wax suspensions, relative to that of the unfilled wax measured for a range of solids fractions. Solid line represents the prediction of a modified Krieger-Dougherty equation, assuming an exponent of 2 . Measurements were made at $120^{\circ} \mathrm{C}$ and a steady shear rate of $100 \mathrm{~s}^{-1}$.

these printing variables on a range of fluids with different properties, to assess their ease of printing.

Figure 6 shows the influence of the signal used to drive the piezoelectric actuator in the ink-jet printing head. The pulse used is an asymmetric square wave, which is subsequently slightly smoothed by the driving electronics. The amplitude of the driving pulse clearly has a linear influence on the velocity of the ejected drop (Fig. 6(a)). The width of the driving pulse shows a more-complex influence on ejected drop velocity (Fig. $6(\mathrm{~b}))$. At a frequency of $10 \mathrm{kHz}$, the pulse repetition period is $100 \mu \mathrm{s}$ and a peak in drop velocity occurs with a pulse width in the range of 20-30 $\mu \mathrm{s}$. The peak width for maximum velocity has a different value for different fluids. In Fig. 6(c), the driving frequency (or pulse repetition rate) has a very strong influence on ejected drop velocity. There is a distinct periodicity in the frequency at which the maxima in drop velocity occur; this periodicity is also a strong function of the fluid properties. This behavior is characteristic of the acoustic properties of the printing chamber and the fluid inside. The maxima in drop velocity correspond to conditions of resonance, which are dependent on the chamber geometry and the speed of the acoustic wave in the liquid-filled chamber. The speed of this acoustic wave is a composite property of the speed of sound in the liquid and the chamber-wall materials. The speed of sound in a liquid is defined as $v=(B / \rho)^{1 / 2}$, where $B$ is the adiabatic bulk modulus and $\rho$ is the density. Both $B$ and $\rho$ are strongly affected by the addition of particles in suspension; thus, the

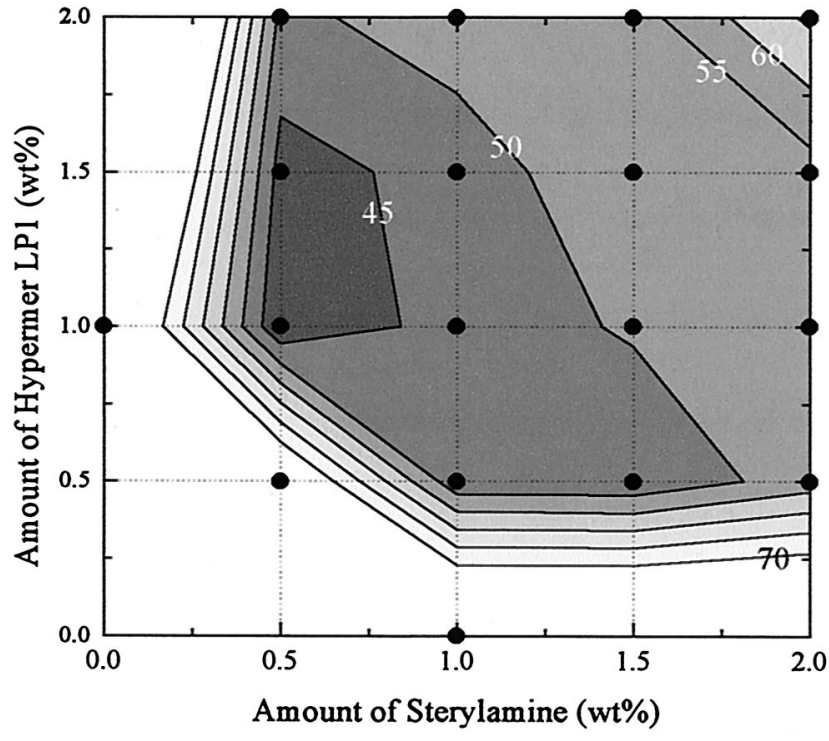

Fig. 4. Contour map showing the steady-state shear viscosity for a 40 vol\% $\mathrm{Al}_{2} \mathrm{O}_{3}$ suspension, as a function of bulk dispersant concentration (calculated by weight of dry powder). Measurements were performed at $120^{\circ} \mathrm{C}$ and a steady shear rate of $80 \mathrm{~s}^{-1}$ for all points indicated (as noted by the solid circles). Contour magnitudes are indicated in units of $\mathrm{mPa} \cdot \mathrm{s}$. Light-colored region at low dispersant concentration indicates viscosities of $>70 \mathrm{mPa} \cdot \mathrm{s}$.

characteristic resonance frequency is expected to be a strong function of the particle content of printable ceramic suspensions. Figure 6(a) shows that, regardless of the relative drop velocity at a given frequency, the ejected velocity is proportional to the exciting voltage and, hence, the magnitude of the pressure pulse. Similar influences of the printing conditions on the ejected drop volume can be measured. By operating near a maximum (or minimum) in drop velocity, the variation that might occur because of unknown changes in the driving parameters is reduced.

These results clearly show that the driving parameters of the ink-jet printing head must be matched to the fluid properties of the material to be printed. Clearly, a known droplet volume must be ejected if our building algorithm is to generate fully dense objects. Also, droplet velocity is important in controlling droplet spreading or the onset of splashing. As a first approximation, printing conditions that produce droplet properties close to those used in the printing of the commercial Protosupport and Protobuild materials, which are used in the printing platform, have been selected for trials.

Table II. Fluid Properties of Proprietary Materials (Protosupport and Protobuild), Parrafin Wax, and Parrafin Wax Loaded with Different Volume Fractions of Alumina Particles

\begin{tabular}{|c|c|c|c|c|c|c|}
\hline \multirow[b]{3}{*}{ Property } & \multicolumn{6}{|c|}{ Value } \\
\hline & \multicolumn{2}{|c|}{ Commercial material } & \multicolumn{4}{|c|}{ Wax } \\
\hline & Protosupport & Protobuild & $0 \%$ & $20 \%$ & $30 \%$ & $40 \%$ \\
\hline Temperature, $T\left({ }^{\circ} \mathrm{C}\right)$ & 110 & 120 & 100 & 100 & 100 & 100 \\
\hline Density, $\rho\left(\mathrm{kg} / \mathrm{m}^{3}\right)$ & 820 & 1150 & 900 & 1500 & 1800 & 2100 \\
\hline Viscosity, $\eta(\mathrm{mPa} \cdot \mathrm{s})^{\dagger}$ & 9 & 15 & 3 & 7 & 15 & 38 \\
\hline Surface tension, $\gamma\left(\mathrm{J} / \mathrm{m}^{2}\right)$ & 0.027 & 0.038 & 0.025 & $0.025^{+}$ & $0.025^{\text {t }}$ & $0.025^{+}$ \\
\hline Revnolds number. $\mathrm{Re}^{\S}$ & 9.57 & 7.84 & 32.59 & 24.23 & 13.03 & 5.80 \\
\hline Weber number, We $\mathrm{e}^{\S}$ & 3.32 & 3.09 & 3.37 & 4.35 & 4.76 & 5.14 \\
\hline $\mathrm{Re} / \mathrm{We}$ & 2.88 & 2.54 & 9.68 & 5.57 & 2.74 & 1.13 \\
\hline$K$ & 5.85 & 5.17 & 8.05 & 9.65 & 9.05 & 7.98 \\
\hline$\xi$ & 1.15 & 1.14 & 1.46 & 1.30 & 1.11 & 0.91 \\
\hline
\end{tabular}

of $3 \mathrm{~m} / \mathrm{s}$ and a characteristic length equal to the ink-jet orifice radius $(l=35 \mu \mathrm{m})$. 


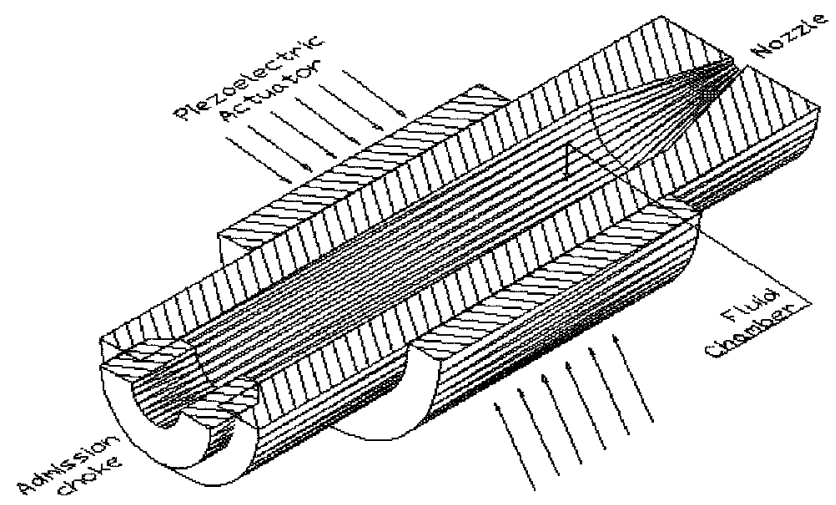

Fig. 5. Isometric section through a typical tubular piezoelectric-actuated ink-jet printing head, sliced parallel to the printing axis (dimensions not to scale).

Figure 7 shows the behavior of droplets ejected from the test station that contains 30 and $40 \mathrm{vol} \%$ alumina particles, under suitable printing conditions. If these images are compared with those in Fig. 1, the $30 \mathrm{vol} \%$ suspension clearly shows behavior that is similar to that of the Protosupport material. Table II shows that the $30 \mathrm{vol} \%$ suspension and Protosupport have very similar Re/We, $K$, and $\xi$ values. The $40 \mathrm{vol} \%$ suspension requires a higher driving frequency and voltage to eject droplets (see Table III). The 40 vol\% suspension also produces droplets, showing an asymmetric ejected tail (Fig. 7(b)). Application of a small overpressure $(\sim 10 \mathrm{kPa}$, or $\sim 0.1 \mathrm{~atm})$ to the feed reservoir was determined to be necessary, to eject droplets with
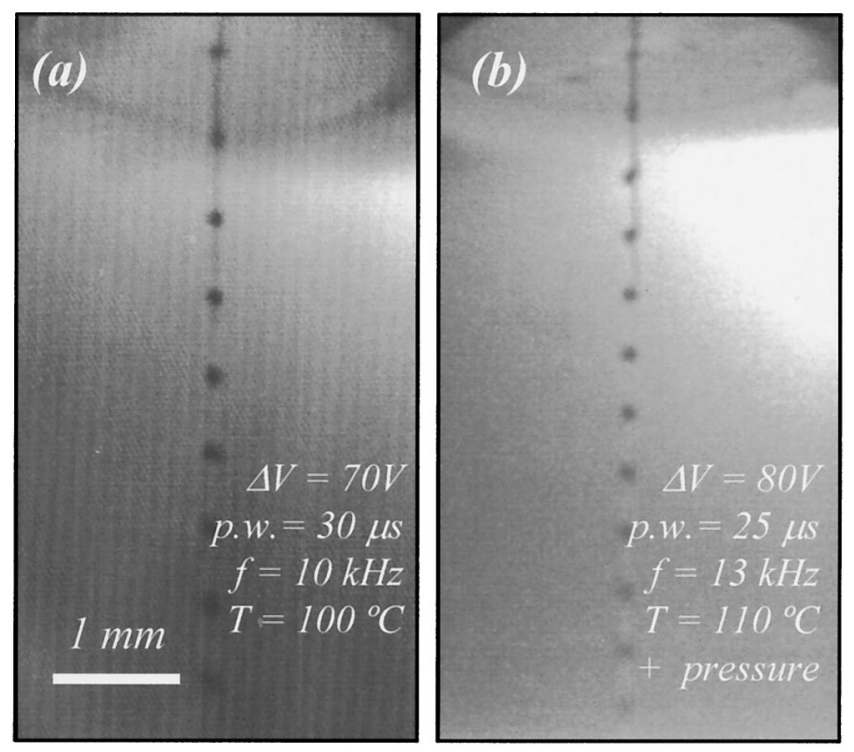

Fig. 7. In situ stroboscopic images of the droplets that form near the ink-jet printing head, using suspensions of $\mathrm{Al}_{2} \mathrm{O}_{3}$ in wax (solids loadings of (a) $30 \mathrm{vol} \%$ and (b) $40 \mathrm{vol} \%$ ).

the 40 vol\% suspension. This pressure was required because the viscosity of the suspension inhibited chamber refilling after each pulse. Note from Table II that, at this particle loading, the Re/We value deviates significantly from those of Protosupport and Protobuild, because of its greater fluid viscosity.
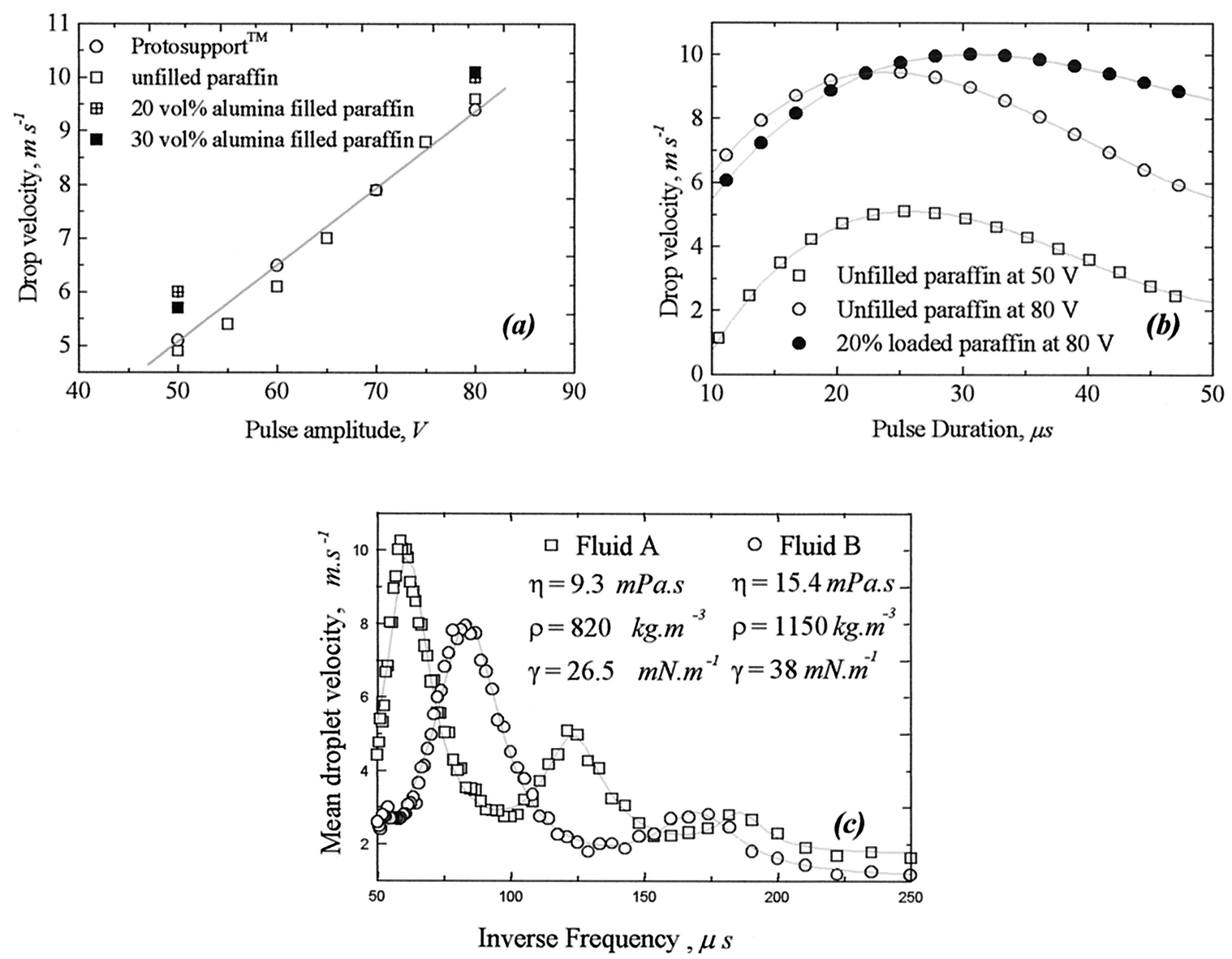

Fig. 6. Parameters that control ejected drop velocity: (a) influence of actuator excitation voltage, (b) influence of excitation pulse duration, and (c) influence of pulse-repetition time (1/frequency) (in Fig. 6(c), fluid A is "Protosupport" and fluid B is "Protobuild"). All trials were conducted at $110^{\circ} \mathrm{C}$; Figs. 6(a) and (b) were obtained at a constant frequency of $10 \mathrm{kHz}$. 
Table III. Optimum Printing Conditions Determined from Printing Trials of the $30 \%$ and $40 \% \mathrm{Al}_{2} \mathrm{O}_{3}$ Suspensions

\begin{tabular}{ccccc}
\hline Material & $\begin{array}{c}\text { Frequency } \\
(\mathrm{kHz})\end{array}$ & $\begin{array}{c}\text { Pulse width } \\
(\mu \mathrm{s})\end{array}$ & $\begin{array}{c}\text { Driving voltage } \\
(\Delta \mathrm{V})\end{array}$ & $\begin{array}{c}\text { Temperature } \\
\left({ }^{\circ} \mathrm{C}\right)\end{array}$ \\
\hline $30 \% \mathrm{Al}_{2} \mathrm{O}_{3}$ & 10 & 30 & 70 & 100 \\
$40 \% \mathrm{Al}_{2} \mathrm{O}_{3}^{\dagger}$ & 13 & 25 & 80 & 110 \\
\hline
\end{tabular}

${ }^{\dagger}$ A small overpressure was applied to the reservoir that contained the fluid.

\section{(3) Printing Trials}

During normal operation, the Modelmaker MM6 Pro printer deposits low-melting-point waxlike liquids. To ensure accurate reproduction of detail and eliminate the propagation of errors introduced by surface roughness, the machine uses a rotary cutter to remove the topmost part of each layer after deposition, to ensure a flat and parallel reference surface before deposition of the next layer. The cutter was deactivated for these printing trials, because of concerns about smearing of the built-up layer. The printer was operated at a frequency of $6 \mathrm{kHz}$, with a firing pulse width of 30 $\mu \mathrm{s}$. These parameters were used with all the fluids printed. However, it is possible to adjust the maximum voltage of the pulse and the temperature at which the ink-jet printing head operates. The conditions used for printing two suspensions of different ceramic volume fraction and those used with the commercial fluids are given in Table IV. In Fig. 8, a range of objects produced by printing the $30 \mathrm{vol} \%$ alumina suspension is displayed. Figure $8(\mathrm{~b})$ shows excellent reproduction of a square honeycomb structure, and, in Fig. 8(c), walls $<100 \mu \mathrm{m}$ thick have been fabricated. The distortion visible in Fig. 8(c) is an artifact of the macrolens used to capture the image. Figure 9 shows the edge-on view of ceramic bodies printed with approximately fifty layers of material. These bodies exhibit good vertical walls and corner definition. The resolution of the vertical corners and edges are a test of the accurate superposition of sequential layers in any layered manufacturing method.

Comparison of the data obtained from these suspensions and the commercial fluids indicates that it was reasonable to expect that the suspensions would print successfully. However, this similarity is defined by several characteristic dimensionless-property groupings obtained from the literature. We used the work of Fromm ${ }^{10}$ to justify the use of the Re/We ratio as a figure of merit. However, earlier work has shown that numerical simulations of ink-jet drop ejection do not show the same results at a constant $\mathrm{Re} / \mathrm{We}$ ratio. ${ }^{11}$ The absolute viscosity is a key measure, and, if this value is too high, jetting may be suppressed for a given Re/We ratio. Clearly, more work is needed to predict ink-jet behavior accurately, especially when highly viscous fluids are used. Most work that simulates ink-jet behavior has also assumed the fluid to exhibit Newtonian properties. This situation is clearly not the case for printing highly filled suspensions where marked shear thinning can occur at high strain rates (see Fig. 2).

Literature values of algorithms that predict splat diameter have been used to determine whether the fluid properties of our suspensions will produce solid objects of the dimensions expected using a commercial printing platform optimized for other fluids. The expression derived by Bhola and Chandra ${ }^{12}$ has been tested against experimental results for droplet impingement using paraffin wax. However, their experiments used droplets $\sim 3 \mathrm{~mm}$ in diameter, which undergo negligible solidification before reaching

Table IV. Operating Conditions for the Printer Used in These Printing Trials

\begin{tabular}{lcccc}
\hline \multicolumn{1}{c}{ Material } & $\begin{array}{c}\text { Frequency } \\
(\mathrm{kHz})\end{array}$ & $\begin{array}{c}\text { Pulse width } \\
(\mu \mathrm{s})\end{array}$ & $\begin{array}{c}\text { Driving voltage } \\
(\Delta \mathrm{V})\end{array}$ & $\begin{array}{c}\text { Temperature } \\
\left({ }^{\circ} \mathrm{C}\right)\end{array}$ \\
\hline Protobuild & 6 & 30 & 50 & 120 \\
Protosupport & 6 & 30 & 60 & 110 \\
$20 \% \mathrm{Al}_{2} \mathrm{O}_{3}$ & 6 & 30 & 60 & 110 \\
$30 \% \mathrm{Al}_{2} \mathrm{O}_{3}$ & 6 & 30 & 70 & 110 \\
\hline
\end{tabular}
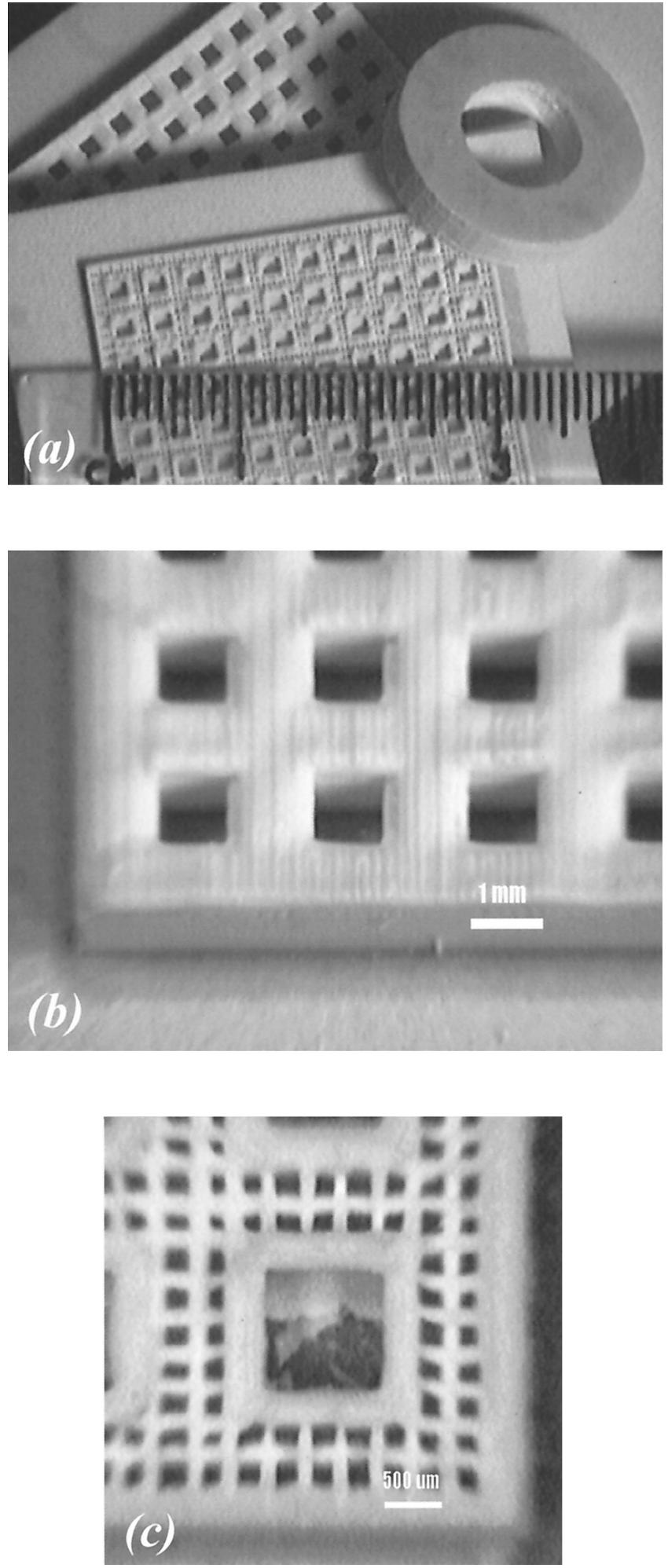

Fig. 8. (a) Examples of unfired ceramic bodies printed from the $30 \mathrm{vol} \%$ $\mathrm{Al}_{2} \mathrm{O}_{3}$ slurries. Figure 8(b) shows the good resolution of straight edges after printing, whereas Fig. 8(c) shows that a minimum wall thickness of $\sim 100 \mu \mathrm{m}$ has been achieved.

their maximum spread on impact. With the Modelmaker MM6 Pro printer, individual droplets have a diameter of $\sim 70 \mu \mathrm{m}$ (Fig. 1); hence, the fraction that solidifies during impact may have a much stronger influence on droplet spreading. This condition has been considered by Schiaffino and Sonin, ${ }^{18}$ who produced dimensionless analytical expressions to calculate the ratio between droplet spreading and solidification time. They found that, although the solidification time of a droplet $25-100 \mu \mathrm{m}$ in size was several 


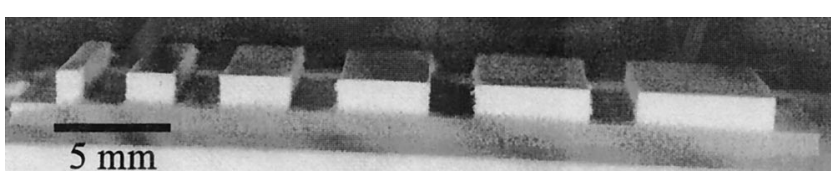

Fig. 9. Rectangular sections of objects $1 \mathrm{~mm}$ in height and 1-6 $\mathrm{mm}$ wide, printed using the 30 -vol\%-solids slurry. Straight vertical edges show that each sequentially printed layer corresponds well with the preceding layers.

orders of magnitude greater than the time taken to reach maximum spreading diameter, this diameter was controlled by solidification of the contact line. Unfortunately, they do not consider the spreading dynamics for materials of the fluid properties used here.

The parameter $K$ (recall Eq. (3)) has been used to determine if splashing is likely to occur. Literature values for the splashing of paraffin wax have not been exceeded, and splashing has been absent in the results reported here. However, in a series of experiments reported elsewhere, ${ }^{9}$ splashing of ceramic slurries during printing at higher impact velocities-and, hence, higher $K$ values than used here-was observed.

Thus, by considering the $\mathrm{Re}$ and We values of the ceramic suspensions and using these values to ensure similarity with the fluids already optimized for use with a commercial ink-jet printing platform, the printing of ceramic suspensions of considerably higher powder loading than previously reported has hence been proven possible. Experiments on dewaxing and sintering objects cast (not printed) from identical alumina-filled waxes have shown that objects with 35 vol\% ceramic loading can be sintered without cracking. Thus, one can be confident that this method can be used to produce sintered ceramic objects. To print objects with solids fractions of $>30 \mathrm{vol} \%$ with the existing printer, modification to the operating parameters of the printer will be required. It should be relatively easy to print the 40 -vol\%-loaded suspensions by applying an overpressure to the ink reservoir and possibly increasing the driving voltage of the piezoelectric driver. A higher volume loading of particles, to reduce shrinkage during sintering, is possible in principle. However, this effort will require further optimization of the suspension rheology, which may possibly be achieved using a carrier wax with a shorter chain length and, hence, lower inherent viscosity.

\section{Conclusions}

Hot-melt ink-jet printing, using a commercial piezoelectric drop-on-demand printer, has been successfully demonstrated as a viable method of producing solid bodies that contain ceramic particles dispersed in low-melting-point waxes. The importance of understanding the influence of the physical properties of the fluid on acoustic resonance within the ink-jet printing chamber has been demonstrated. Excellent spatial resolution and feature rendition has been achieved with a suspension that contained $30 \mathrm{vol} \%$ ceramic particles. It has been shown that suspensions that contain 40 vol\% ceramic powder can be passed through an ink-jet head, but only with the application of further pressure to transport the fluid from the reservoir to the printing chamber.

\section{Acknowledgments}

The authors thank Sanders Design International for assisting in the design and construction of the jet-test station and providing much information about the Modelmaker printing platform. The authors would also like to thank Alcan Chemicals, who supplied the alumina powder used.

\section{References}

${ }^{1}$ E. Sachs, M. Cima, P. Williams, D. Brancazio, and J. Cornie, "3-Dimensional Printing-Rapid Tooling and Prototypes Directly from a CAD Model," ASME J. Eng. Ind., 114, 481-88 (1992).

${ }^{2}$ J. Yoo, K. Cho, W. Bae, M. Cima, and S. Suresh, "Transformation-Toughened Ceramic Multilayers with Compositional Gradients," J. Am. Ceram. Soc., 81, 21-32 (1998)

${ }^{3}$ W. D. Teng, M. J. Edirisinghe, and J. R. G. Evans, "Optimization of Dispersion and Viscosity of a Ceramic Ink-Jet Printing Ink," J. Am. Ceram. Soc., 80, 486-94 (1997)

${ }^{4}$ Q. F. Xiang, J. R. G. Evans, M. J. Edirisinghe, and P. F. Blazdell, "Solid Freeforming of Ceramics Using a Drop-on-Demand Jet Printer," Proc. Inst. Mech. Eng., 211, 211-14 (1997).

${ }^{5}$ C. E. Slade and J. R. G. Evans, "Freeforming Ceramics Using a Thermal Jet Printer," J. Mater. Sci. Lett., 17, 1669-71 (1998).

${ }^{6}$ M. Mott, J. H. Song, and J. R. G. Evans, "Microengineering of Ceramics by Direct Ink-Jet Printing," J. Am. Ceram. Soc., 82, 1653-58 (1999).

${ }^{7}$ J. Windle and B. Derby, "Ink-Jet Printing of PZT Aqueous Ceramic Suspensions," J. Mater. Sci. Lett., 18, 87-90 (1999).

${ }^{8}$ K. A. M. Seerden, N. Reis, B. Derby, P. S. Grant, J. W. Halloran, and J. R. G. Evans, "Direct Ink-Jet Deposition of Ceramic Green Bodies: Part 1. Formulation of Build Materials," Mater. Res. Soc. Symp. Proc., 542, 141-46 (1999).

${ }^{9}$ N. Reis, K. A. M. Seerden, B. Derby, P. S. Grant, J. W. Halloran, and J. R. G. Evans, "Direct Ink-Jet Deposition of Ceramic Green Bodies: Part 2. Jet Behaviour and Deposit Formation," Mater. Res. Soc. Symp. Proc., 542, 147-52 (1999).

${ }^{10}$ J. E. Fromm, "Numerical Calculation of the Fluid Dynamics of Drop-on-Demand Jets," IBM J. Res. Dev., 28, 322-33 (1984).

${ }^{11}$ N. Reis and B. Derby, "Ink-Jet Deposition of Ceramic Suspensions: Modelling and Experiments of Droplet Formation," Mater. Res. Soc. Symp. Proc., 625, 117-22 (2000).

${ }^{12}$ R. Bhola and S. Chandra, "Parameters Controlling Solidification of Molten Wax Droplets Falling on a Solid Surface," J. Mater. Sci., 34, 4883-94 (1999).

${ }^{13}$ C. Mundo, M. Sommerfield, and C. Tropea, "Droplet-Wall Collisions-Experimental Studies of the Deformation and Break-Up Process," Int. J. Multiphase Flow, 21, 151-73 (1995).

${ }^{14}$ C. D. Stow and M. G. Hadfield, "An Experimental Investigation of Fluid Flow Resulting from the Impact of a Water Droplet with an Unyielding Dry Surface," Proc. R. Soc. London A, 373, 419 (1981).

${ }^{15}$ J. H. Song and J. R. G. Evans, "Ultrafine Ceramic Powder Injection Moulding: The Role of Dispersants," J. Rheol. (NY), 40, 131-52 (1996).

${ }^{16}$ J. D. Schofield, Eur. Pat. No. 0240160, April 17, 1991.

${ }^{17}$ L. Bergstrom, "Rheological Properties of Concentrated Non-Aqueous Silicon Nitride Suspensions," J. Am. Ceram. Soc., 79, 3033-40 (1996).

${ }^{18}$ S. Schiaffino and A. A. Sonin, "Molten Droplet Deposition and Solidification at Low Weber Numbers," Phys. Fluids, 9, 3172-87 (1997). 